\title{
Мощные СВЧ и переключающие транзисторы на основе нитрида галлия
}

\author{
В. Бельков ${ }^{1}$, А. Цоцорин, к. Ф.-м. н. ${ }^{2}$, \\ И. Семейкин, к. т.н. ${ }^{3}$, М. Черных, к. т. н. ${ }^{4}$
} УДК 621.38 | ВАК 05.27 .01

\begin{abstract}
В АО "НИИЭТ", которое является разработчиком, изготовителем и поставщиком изделий электронной компонентной базы, получен ряд мощных СВЧ-транзисторов мощностью 400 Вт в диапазоне частот до 1,6 ГГц и мощностью до 80 Вт в диапазоне частот до 12 ГГц. А также ряд силовых переключающих транзисторов с напряжением сток-исток 100, 200 и 650 В.
\end{abstract}

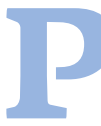

азвитие технологии создания приборов на основе нитрида галлия (GaN) в последние несколько десятилетий позволило получать транзисторные структуры, значительно превосходящие по характеристикам имеющиеся приборы на основе кремния и арсенида галлия. С одной стороны, появление высококачественных структур нитрида галлия на карбидкремниевых подложках дает возможность создавать приборы высокой мощности в S-, С-и Х-диапазонах частот. С другой стороны, технология выращивания нитрида галлия на кремниевых подложках позволяет применять этот материал в силовой электронике.

\section{МОЩНЫЕ СВЧ-ПРИБОРЫ НА ОСНОВЕ GaN}

Обладая высокой подвижностью носителей заряда, а также высокими значениями критического поля пробоя, нитрид галлия идеально подходит для создания мощных СВЧ-транзисторов. Из-за сложности выращивания собственных подложек нитрида галлия для мощных СВЧ-транзисторов чаще всего используют подложки из чистого карбида кремния. Этот материал обладает низким рассогласованием кристаллических решеток с нитридом галлия, что позволяет минимизировать количество переходных слоев при эпитаксиальном выращивании. Карбид кремния обладает высокой теплопроводностью, что позволяет получать высокие значения удельной мощности в приборах

АО «нИИЭТ», инженер-технолог 2 категории.

АО «НИИЭТ», начальник отдела.

АО «НИИЭТ», технический директор.

АО «нИИЭТ», начальник лаборатории. с подложкой на его основе [1]. В то же время подложки карбида кремния до сих пор имеют относительно высокую стоимость, что во многом определяет цену готовыхтранзисторов

Поперечное сечение GaN HEMT-структуры изображено на рис. 1. Характерным элементом структуры являются сквозные отверстия, соединяющие истоковые области с подложкой транзистора. Такое решение позволяет значительно снизить индуктивность истока и упростить монтаж кристалла в корпус [2]

Важной частью мощного СВЧ-транзистора являются внутрикорпусные цепи согласования. Для примера на рис. 2 приведены внутрикорпусные схемы согласования транзистора 6П9143АЗ, представляющие собой сумматоры, делители мощности и МдП-конденсаторы. Применение такой схемы позволяет приблизить импеданс транзистора к 50 Ом в требуемом диапазоне частот.

Параметры разработанных в АО «НИИЭТ» мощных СВч-транзисторов на основе нитрида галлия приведены в табл. 1. В ней указаны минимальные значения коэффициента усиления по мощности и коэффициента

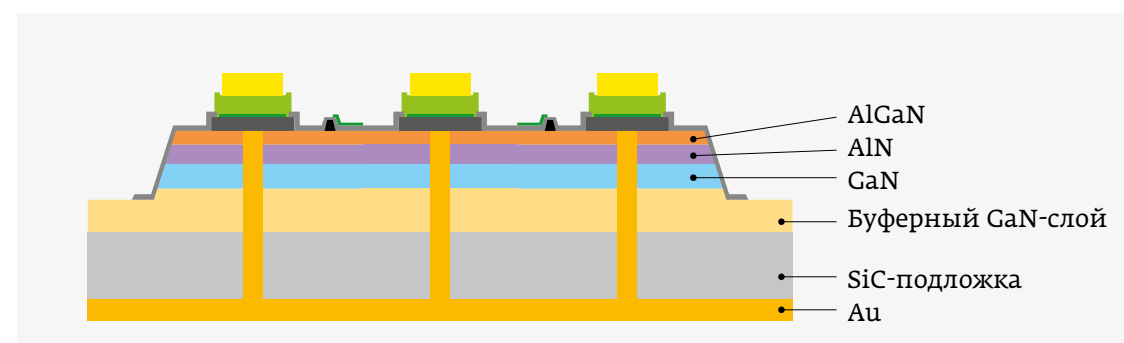

Рис. 1. Поперечное сечение транзисторной ячейки с металлизированными сквозными отверстиями в активной области 
полезного действия стока транзистора, в отличие от зарубежных спецификаций, приводящих типовые значения.

\section{ТРАНЗИСТОРЫ НА ОСНОВЕ СТРУКТУР GaN-on-Si}

Высокие значения пробивных напряжений при относительно низком сопротивлении в открытом состоянии делают приборы на основе нитрида галлия перспективными для применения в силовой электронике. Так как нитрид галлия отличается от кремния повышенной подвижностью электронов и увеличенной электрической прочностью, то при заданных значениях сопротивления и пробивного напряжения GaN-транзистор будет иметь меньшие размеры по сравнению с кремниевым аналогом. Обратным эффектом является значительное снижение теплопроводности подложки, что для транзисторов, работающих в ключевом режиме, не так критично, как для транзисторов, работающих в усилительном режиме. GaN-транзисторы, работающие в ключевом режиме, также обладают чрезвычайно высокой скоростью переключений и минимальным временем обратного восстановления, что является важным условием для уменьшения потерь и повышения эффективности [3].

Можно выделить следующие основные достоинства GaN силовых транзисторов по сравнению с Si-аналогами:

- сопротивление открытого канала $R_{\text {on }}$ у транзисторов на основе GaN-структур имеет очень низкое значение, вследствие чего минимизируется количество статических потерь;

- высокая скорость переключения вследствие минимальной входной емкости, что обеспечивает их применение в приборах с большими выходными токами и увеличением рабочих частот до нескольких сотен мегагерц;

- при повышении рабочих частот также возможно и повышение эффективности ключа. Это позволит снизить значение емкостей и индуктивностей выходных фильтров, вследствие чего возможно снизить габаритные размеры транзистора без потери рабочих параметров.

Таблица 1. Основные параметры мощных СBЧ GaN-транзисторов АО «НИИЭТ»

\begin{tabular}{|c|c|c|c|c|c|}
\hline Прибор & $U_{\text {пит }}$, B & $f_{\text {тест }}$, МГц & $\mathrm{P}_{\text {вых }}, \mathrm{BT}$ & $\mathrm{K}_{\text {ур мин }}$, ДБ & КПД \\
\hline 6П9140A & 50 & 1,6 & 400 & 12 & 60 \\
\hline 6П9141А1 & 28 & 1,7 & 80 & 17 & 65 \\
\hline 6П9141Б1 & 28 & 2,5 & 60 & 15 & 65 \\
\hline 6П9142А2 & 28 & 4 & 20 & 13 & 45 \\
\hline 6П9142Б2 & 28 & 4 & 2 & 13,5 & 45 \\
\hline 6П9143АЗ & 28 & $7,7-8,7$ & 30 & 12 & 35 \\
\hline 6П9143Б2 & 28 & $7,7-8,7$ & 5 & 13 & 30 \\
\hline 6П9144А4 & 28 & 12 & 0,5 & 13,5 & 20 \\
\hline 6П9144Б4 & 28 & 12 & 0,12 & 14,5 & 20 \\
\hline 6П9145А2 & 28 & 4 & 5 & 13 & 45 \\
\hline 6П9145Б2 & 28 & 4 & 10 & 10 & 45 \\
\hline 6П9145В2 & 28 & 4 & 15 & 10 & 45 \\
\hline 6П9145Г2 & 28 & 4 & 25 & 9 & 45 \\
\hline 6П9146А1 & 28 & 1,5 & 100 & 13 & 45 \\
\hline
\end{tabular}




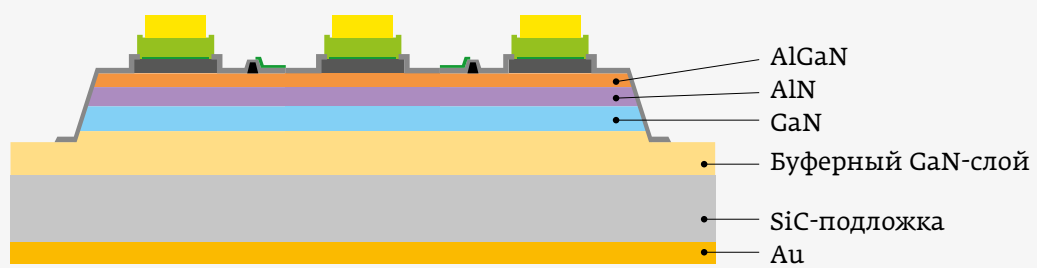

Рис. 3. Поперечное сечение ячейки силового GaN-транзистора

Специалистами АО "НИИЭТ» разработан ряд переключающих GaN-транзисторов с напряжением 100, 200 и 650 В и низким значением $R_{\text {on }}$. Данные транзисторы разрабатывались для поверхностного монтажа (SMD) с использованием металлокерамических корпусов В планах на будущее доработка топологии силовых кристаллов для возможности их монтажа по технологии Flip-Chip, что обеспечит сни-

Однако, несмотря на все преимущества GaN силовых транзисторов, прогресс в данном направлении в значительной мере ограничивался высокой стоимостью таких приборов. Но с появлением технологии выращивания низкодефектных эпитаксиальных структур нитрида галлия на кремнии стало возможным значительное снижение стоимости конечного транзистора.

Схематическое изображение GaN транзисторной структуры на кремниевой подложке приведено на рис. 3. Ключевым различием относительно структуры на рис. 1 является отсутствие сквозных металлизированных отверстий в областях стока структуры. жение паразитных параметров и поспособствует уменьшению габаритных размеров конечного устройства.

\section{ЛИТЕРАТУРА}

1. Тарасов С. В., Дикарев В. И., Цоцорин А. Н. Мощные GaN-транзисторы для применения в перспективных системах связи и радиолокации // Электронные компоненты. 2017. № 7. С. 80-83.

2. Тарасов С. В. и др. Мощные GaN-транзисторы S-, C-, Х-диапазонов частот // Электроника и микроэлектроника СВ4. 2018. Спецвыпуск. С. 88-94.

3. Schweber B. GaN Power Devices: Potential, Benefits, and Keys to Successful // EIU EUROPE. 2018. No. 1. P. 10-13.

\section{КНИГИ ИЗДАТЕЛЬСТВА «ТЕХНОСФЕРА»}

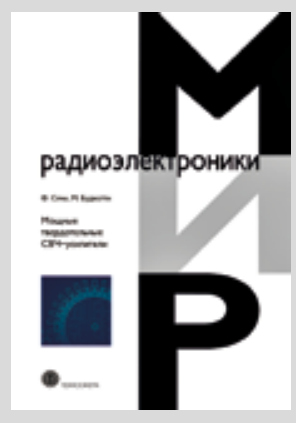

Цена 975 руб.

\section{МОЩНЫЕ ТВЕРДОТЕЛЬНЫЕ} СВЧ-УСИЛИТЕЛИ

\section{Сечи Ф., Буджатти М.}

При поддержке АО «НПП "Исток» им. Шокина»

\section{Перевод с англ. под ред. д. т. н. А. А. Борисова}

В книге рассмотрены все традиционные вопросы, связанные с разработкой усилителей мощности, начиная от получения моделей приборов на большом сигнале и заканчивая обсуждением сумматоров мощности и методов проектирования.

Большое внимание в издании уделено рассмотрению физических основ приборов, фазовых шумов, схем смещения и тепловому проектированию. Также в книге особое внимание уделяется рассмотрению фундаментальных принципов. Издание затрагивает необычайно большое количество областей, связанных с физикой полупроводников и активных устройств.

Книга представляет интерес для специалистов, которые занимаются разработкой усилителей мощности для базовых станций сотовой связи. В особенности это относится к рассмотрению моделей на больших сигналах, проблем, связанных с фазовыми шумами, методов проектирования усилителей мощности, специальных конструкций усилителей мощности и теплового проектирования. Также данная книга может послужить в качестве справочного пособия при углубленном изучении СВЧ-устройств. 


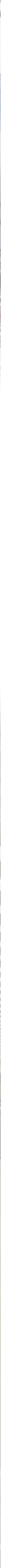

